\title{
Dementia and Cognitive Impairment Reduction after Laser Transcatheter Treatment of Alzheimer's Disease
}

\author{
Ivan V. Maksimovich \\ Clinic of Cardiovascular Diseases Named after Most Holy John Tobolsky, Moscow, Russia \\ Email: carvasc@yandex.ru
}

Received 4 April 2015; accepted 1 June 2015; published 5 June 2015

Copyright (C) 2015 by author and Scientific Research Publishing Inc.

This work is licensed under the Creative Commons Attribution International License (CC BY). http://creativecommons.org/licenses/by/4.0/

(c) (i) Open Access

\section{Abstract}

Reduced cerebral perfusion and microcirculation are found among AD causes, which should be considered in the development of new treatments for the disease. 165 patients with AD were examined. The examination plan included clinical assessment of dementia severity (CDR), cognitive function assessment (MMSE), laboratory examination, cerebral scintigraphy (SG), rheoencephalography (REG), cerebral CT and MRI, morphometric AD stages assessment (TDR) and cerebral multi-gated angiography (MUGA). 89 patients aged 34 - 79 (average age 67) were selected for the treatment: $31(34.83 \%)$ male, $58(65.17 \%)$ female patients. According to their AD stage, the patients were divided into: TDR-0 (preclinical stage)-10 (11.24\%) patients, TDR-1 (early stage with mild dementia, mild cognitive impairment) $-28(31.46 \%)$ patients, TDR-2 (medium stage with moderate dementia, cognitive impairment sufficiently persistent) $-34(38.20 \%)$ patients, TDR-3 (late stage with sufficiently severe dementia and cognitive impairment) $-17(19.10 \%)$ patients. Test Group-46 (51.68\%) patients-had transcatheter treatment with low-energy lasers. Control Group-43 (48.31\%) - had conservative treatment with Memantin and Rivastigmine. The Test Group had cerebral microcirculation improvement leading to permanent dementia reduction and cognitive recovery which allowed transferring the patients to a lighter TDR group or withdrawing them from the scale. Control Group patients with earlier AD stages (TDR-0, TDR-1, TDR-2) obtained stabilization for a period of 6 months-3 years, with subsequent growth of dementia and cognitive impairment; patients with late AD stage (TDR-3) showed further increase of cognitive impairment and dementia. Transcatheter treatment allows reducing the effects of dyscirculatory angiopathy of Alzheimer's type (DAAT) improving cerebral microcirculation and metabolism, which leads to permanent dementia regression and cognitive impairment reduction. These data show that AD treatment should be comprehensive and aimed at both the recovery of cerebral microcirculation and blood supply and the normalization of amyloid beta metabolism in the cerebral tissue. 


\section{Keywords}

\section{Alzheimer's Disease, Dementia, Vascular Dysfunction, Dyscirculatory Angiopathy of Alzheimer's Type, DAAT, TDR, Temporal Lobes Atrophy, Laser Revascularization}

\section{Introduction}

Recently, Alzheimer's disease (AD) has become more widespread among the population; about 500,000 new cases are going to appear only in the US in the coming year [1]. The causes of AD have not been fully explored so far. An increased risk of AD development is usually associated with tau, apoE4 (apolipoprotein E4) allele, the accumulation of amyloid beta in the cerebral tissue, and the development of cerebral vascular dysfunction [2] [3]. The ideas that disorders of the brain vascular system played an important role in the etiology and pathogenesis of this disease were expressed quite a long time ago. Thus, in the 30s of the last century, F. Morel introduced the term and described dysoric, or drusoid angiopathy in patients with $\mathrm{AD}$ [4]. In recent years, this issue has been given much more attention, and a large number of studies dedicated to vascular disorders in the etiology and pathogenesis of AD have been conducted accordingly [5]-[16].

Physiologically, the brain is the most highly perfused organ in the human body. In the quiescent state, the minute volume of blood obtained by the brain is about $750 \mathrm{ml}$. Almost $15 \%$ of the total minute volume is accounted for by an organ, which is $2 \%$ of body weight. At that, the gray matter of the human brain consumes $20 \%$ of all oxygen consumed by the whole body [17]. The blood supply of the cerebral cortex and certain areas of gray matter is $300-400 \mathrm{ml} / \mathrm{min} / 100 \mathrm{gr}$ of the matter. The blood supply of the white matter is less and is about $20 \%-25 \%$ of the gray matter perfusion. Large arteries only transport blood, but small arteries and capillaries deep in the tissue carry out sustenance and gas supply. One cubic centimeter of the brain matter contains 12 - 27 small arteries but 3 - 4 thousand of capillaries, with normally almost complete absence of arteriovenous shunts [17]-[20].

Due to this feature of the blood supply, the brain is extremely sensitive to disorders in blood and capillary blood flow, and even a slight decrease in the inflow of arterial blood quickly leads to the development of metabolic disorders, hypoxia and tissue ischemia [20].

Physiologically, in case of acute local loss of blood supply to a particular area of the brain, there develops terminal ischemia and stroke. In case of slow, gradual, partial reduction of bandwidth of the distal arterial bed, stroke does not usually develop; at the same time, the inflowing blood cannot pass through the capillaries completely, so its excessive volume is partially dumped into the venous system. This process is accompanied by the development of a natural compensatory regional reaction of the body-the opening of arteriovenous shunts [8]-[10]. Such arterial blood shunting, along with restricted arterial and capillary blood flow, also contributes to the development of specific brain tissue hypoxia.

Another physiological protective body reaction aimed at reducing the distal blood supply is a natural development of angiogenesis that is accompanied by the opening of additional collaterals and capillaries allowing a roundabout way to increase the blood flow to the hypovascularized area, but this compensatory mechanism is slow and is not always on time to operate [21].

Unlike other lesions, during AD such disorders of distal arterial and capillary blood supply in the brain have their own characteristics and are called "dyscirculatory angiopathy of Alzheimer's type" (DAAT) [10] [22]-[24].

Even at the pre-clinical stage of the disease, the number of capillaries is reduced and extensive hypovascular zones are formed in the temporal and frontoparietal regions of the brain [5] [8] [10]-[12]. Some authors link this process to the presence of apoE4 (apolipoprotein E4) allele, the early deposition of amyloid beta in the walls of blood vessels, other authors attribute this to congenital vascular pathology [2] [3] [8] [10] [11]. In the same cerebral regions, arteriovenous shunts are formed leading to early dumping of arterial blood into the venous channel [10] [22]. Due to the venous bed overflow, abnormal expansion of large tributaries occurs contributing to the development of venous stasis in these basins [23]. Besides, such patients have large loop formations in the distal regions of anterior and middle cerebral arteries [10] [22]. The process is accompanied by accumulation of vasculotoxic and neurotoxic molecules in the cerebral tissue leading to beta amyloid metabolism disruption, the result of which is a decrease in its excretion and an increase in its accumulation [2] [25] [26]. Because of the spe- 
cificity of vascular lesions in $\mathrm{AD}$ and the presence of multiple arteriovenous shunts, the natural, physiological angiogenesis has no time to develop and the disease progresses leading to the accumulation of amyloid beta, neurodegenerative and atrophic changes [11] [27] [28]. This process begins to develop many years before the first signs of AD [29] [30]. It is possible that it is innate and commences in the first years of life, or at an early age [30] [31]. It should be noted that other brain lesions are not characterized by such changes in the vascular system [8] [10] [14] [22].

In the development of $\mathrm{AD}$ treatment, the importance of vascular changes in the etiology and pathogenesis of the disease has not always been taken into account. The impact of drugs on the brain blood supply is not efficient enough, and therefore specific vasoactive therapy is rarely used for AD treatment. Only in the last decade, there appeared studies aimed at developing non-drug treatments for dementia, cognitive impairment and $\mathrm{AD}$, at restoring the distal arterial and capillary blood supply, as well as at the restoration of structural and metabolic processes in the cerebral tissue [32]-[38].

This paper is dedicated to the impact of the recovery of the distal arterial and capillary blood supply of the brain in $\mathrm{AD}$ by means of transcatheter laser treatment, follow-up development of dementia and cognitive impairment, as well as the comparison of this method with the common conservative treatment.

\section{Materials and Methods}

All the examination and all endovascular interventions have been carried out with the approval of the Ethics Committee, as well as with the consent of the examined and treated patients and their relatives.

Criteria for the selection of patients:

1) Consent of the patient and his/her relatives to carry out the examination and treatment;

2) The patient's medical condition allowing the examination and treatment;

3) The severity of dementia, cognitive impairment, atrophic changes in the temporal and frontoparietal brain regions according to the classification "The Tomography Dementia Rating scale” (TDR) [39] [40].

Of 165 patients applying for the treatment, 89 patients aged 34 to 79 (average age 67) were selected, 31 (34.83\%) male and 58 (65.17\%) female patients.

The group included patients without serious comorbidities, with a satisfactory medical condition in accordance with their age group.

\subsection{Patients Examination Plan}

The examination plan included the following methods:

- Clinical assessment of dementia severity was made according to the Clinical Dementia Rating scale (CDR) [41]. Primary examination was conducted on the patient's admission day, secondary ones-before the patient's discharge and then at intervals of 6 - 12 months.

- Assessment of cognitive functions was conducted by means of Mini-Mental State Examination (MMSE) [42]. Primary examination was conducted on the patient's admission day, secondary ones—before the patient's discharge and then at intervals of $6-12$ months.

- Laboratory examination was performed according to the schemes generally accepted in iterventional neuroangiology and included coagulologic, biochemical and clinical tests carried out at the patient's admission and then when necessary [30] [33] [34].

- Scintrigraphy of the brain (SG) was carried out on a gamma camera (Ohio Nuclear, US) following the classical method, in dynamic and static mode, with TC 99M pertechnetat 555 [30] [34]. The patient was examined at his/her admission and then at intervals of $6-12$ months.

- Rheoencephalography (REG) was conducted by means of "Reospektr-8" (Neurosoft, Russia) in accordance with the standard automated method with the identification of pulse blood flow disorders in the cerebral hemispheres [33] [34]. Primary examination was conducted at the patient's admission, secondary ones-before the patient's discharge and then at intervals of 6 - 12 months.

- CT and MRI of the brain were performed on "Somatom" (Siemens), "Hi Speed" (GE), "Tomoscan" (Philips), "Apetro Eterna” (Hitachi) using the ATAA (Advance Tomo Area Analysis), which allows to determine the percentage of atrophic changes in the temporal lobes in comparison with their natural volume in this patient [14] [34] [40] [43]. The patient was examined at his/her admission and then at intervals of 6 - 12 months.

- MUGA of the brain was performed on apparatus "Advantx" (GE) following the classical method of transfe- 
moral access. Synchronously, taking into account the start and the rate of administration, 10 - $12 \mathrm{ml}$ of $\mathrm{Om}$ nipack 350 was introduced intra-carotidally and 7 - $8 \mathrm{ml}$ intra-vertebrally. The registration was carried out in direct and side projections in constant subtraction mode at a speed of 25 frames per second. Further on, frame by frame analysis of the angiograms received in each phase contrast was conducted [8] [10] [21]. Capillary density contrast analysis was performed at the corresponding phase by means of an automatic method using computer program "Angio Vision” based on the determination of the degree of blackening of the corresponding part of the image [10] [14] [22] [24]. Primary examination was conducted at the patient's admission, secondary ones-in 2 - 6 years after the treatment.

- The morphometric determination of AD stages was performed in accordance with the Tomography Dementia Rating Scale (TDR) [39] [40]. The method allows determining the severity of atrophic changes in the temporal lobes according to CT and MRI of the brain, thus enabling to determine the stage of developed dementia in AD. The method also allows to differentiate the clinical stage of the disease, as well as to identify its pre-clinical stage [43]. Primary examination was conducted at the patient's admission, secondary ones-at intervals of 6 - 12 months.

\subsection{Results of Examination of Patients}

CDR testing detected signs of dementia in 79 (88.76\%) patients.

MMSE detected signs of cognitive impairment in all 89 (100\%) patients.

Laboratory examination revealed no significant abnormalities.

SG detected decreased blood flow in the cerebral hemispheres in all 89 (100\%) patients.

REG revealed a decrease in the pulse blood volume in carotid basinls in all $89(100 \%)$ patients.

CT and MRI of the brain showed involutive changes accompanied by atrophy of the temporal lobes, extension of the Sylvian fissure and subarachnoid space in the temporal and frontoparietal regions in all 89 (100\%) patients.

Morphometric assessment of stages of dementia in AD was performed in all 89 (100\%) patients.

MUGA showed the symptoms of dyscirculatory angiopathy of Alzheimer's type (DAAT) [10]-[24] in all 89 (100\%) patients, namely:

- absence of (or they were poorly expressed) atherosclerotic changes of extra and intracranial arteries in all 89 (100\%) patients;

- depletion of the capillary bed in the projection of the hippocampus and frontal-parietal brain regions manifested in reduction of the capillary phase contrast as poorly vascularized areas in all 89 (100\%) patients;

- multiple arterio-venous shunts in the basin of the front villous artery supplying the hippocampus and in the basin of the arterial branches supplying the frontoparietal brain regions in all 89 (100\%) patients;

- early venous dumping of arterial blood into the venous bed which is characterized by simultaneous filling of arteries and veins in the temporal and frontoparietal regions in all 89 (100\%) patients;

- development of abnormally enlarged lateral veins that receive blood from the arterio-venous shunts in the temporal and frontoparietal regions in 81 (91.01\%) patients;

- anomalous venous stasis on the border of the frontal and parietal lobe due to excessively high blood influx from the arterio-venous shunts, 80 (89.88\%) patients;

- increased loop formation of distal intracranial arterial branches in 72 (80.90\%) patients.

\subsection{Patient Selection}

The patients were divided into the following groups:

- preclinical AD stage-TDR-0: patients with increasing memory disorders without apparent manifestations of dementia but with cognitive decline (MMSE 26 - 28 points) as well as involutive changes in the brain accompanied by $4 \%$ - 8\% temporal lobes atrophy-10 (11.24\%) patients (in the present research, the patients were direct descendants of patients with $\mathrm{AD}$ and had a high likelihood of developing the disease);

- early AD stage-TDR-1: patients with mild dementia, mild cognitive impairment (MMSE 20 - 25 points), which corresponds to CDR-1, had previously been diagnosed with AD, medical history did not exceed 2 years, 9\% - 18\% temporal lobes atrophy-28 (31.46\%) patients;

- medium AD stage-TDR-2: patients with moderate dementia, sufficiently resistant cognitive impairment (MMSE 12 - 19 points), which corresponds to CDR-2, had previously been diagnosed with AD, medical history of 2 to 6 years, 19\% - 32\% temporal lobes atrophy-34 (38.20\%) patients; 
- late AD stage-TDR-3: patients with a fairly severe dementia, gross cognitive impairment (MMSE 7 - 11 points), which corresponds to CDR-3, had previously been diagnosed with $\mathrm{AD}$, medical history of 7 to 12 years, 33\% - $62 \%$ temporal lobes atrophy-17 (19.10\%) patients.

\subsubsection{Test Group}

Test group: 46 (51.68\%) patients (group TDR-0: 4 patients; TDR-1: 15 patients; TDR-2: 20 patients; TDR-3: 7 patients) — underwent transcatheter laser treatment.

For patients at pre-clinical AD stage (group TDR-0), transcatheter laser intervention was carried out preventively, taking into account the growing memory impairment. In patients suffering from AD (groups TDR-1, TDR-2, TDR-3), the interventions were performed in the period from 1 year to 12 years after the first symptoms of the disease.

Transcatheter Treatment Method [32]-[34].

Under local anesthesia, according to Seldinger's classical method, the common femoral artery is punctured and catheterized with an installation of an introducer with a 6 - $9 \mathrm{~F}$ diameter. Through this introducer and through coaxially brought guiding catheters installed in the general and further on in the internal carotid artery, is brought a thin flexible fiber-optic lightguided instrument with a diameter of 25 - 100 micrometers, coupled with the laser unit. The fiber-optic instrument is first guided to the proximal and then to the distal sites of the anterior and middle cerebral arteries, where the laser treatment is carried out. The distal end of the lightguided instrument is constantly washed with heparinized $0.9 \%$ NaCL solution. To carry out X-ray TV control, small doses of radiopaque substance are periodically introduced. Laser irradiation is carried out using low-energy lasers in the visible region of the spectrum, of $20-\mathrm{mw}$ power, operating in continuous, or pulsed, or combined modes. The exposure time takes about 20 - 40 minutes. After the transcatheter intervention the patient undergoes repeated cerebral multi-gated angiography following the procedure described above, the results of which determine the degree of revascularization and restoration of the microcirculatory bed [34]. We assume that if the capillary blood flow has not been fully restored during the first attempt of the intervention, the manipulation can be repeated, but it was not necessary during the transcatheter interventions described.

The treatment was followed by common interventional neuroangiology schemes. The patients underwent conventional desagrigant, anticoagulant, vasodilator and nootropic therapy including Aspirin, Heparin, indirect anticoagulants (depending on the blood coagulation indicators), Pentoxifylline $100 \mathrm{mg}$, Complamin $150 \mathrm{mg}$, Inosin $200 \mathrm{mg}$, Nootropil (Piracetam) $1200 \mathrm{mg}$ (or Gliatilin $1000 \mathrm{mg}$ ) intravenously, with a drop counter, No. 10 15 , and then they took pills. Subsequent 3-months' courses of pills were repeated twice a year. The patients did not receive any specific drugs aimed at the treatment of $\mathrm{AD}$.

\subsubsection{Control Group}

Control group: 43 (48.31\%) patients (group TDR-0: 6 patients, TDR-1: 13 patients, TDR-2: 14 patients, TDR-3: 10 patients)—underwent conservative treatment.

Therapeutic treatment was carried out according to common schemes and dosages [44] [45]. Patients from group CDR-0 received nootropics: Nootropil (Piracetam) 2400 mg per day (3 - 4 months' courses), or Gliatilin 1200 mg per day (4 - 6 months' courses). Patients from groups CDR-1, CDR-2, CDR-3 took Memantin 5 - 20 mg per day as a neuroprotective drug, or Rivastigmine 3 - $12 \mathrm{mg}$ per day as a cholinergic drug. At the same time, patients of all groups received vasoactive drugs Pentoxifylline $800 \mathrm{mg}$ daily, 3 months' courses, and Complamin $450 \mathrm{mg}$ daily, 3 months' courses repeated twice a year.

\section{Results}

\subsection{Test Group}

\subsubsection{Immediate Results}

We did not have any complications in any case during the transcatheter interventions or in the subsequent longterm period.

According to cerebral MUGA, a good immediate angiographic result manifested in the stimulation of natural angiogenesis, improvement and restoration of collateral and capillary blood flow, reduction of arteriovenous shunts and improved venous outflow, was obtained in all 46 (100\%) patients (Figure 1-Figure 4). 


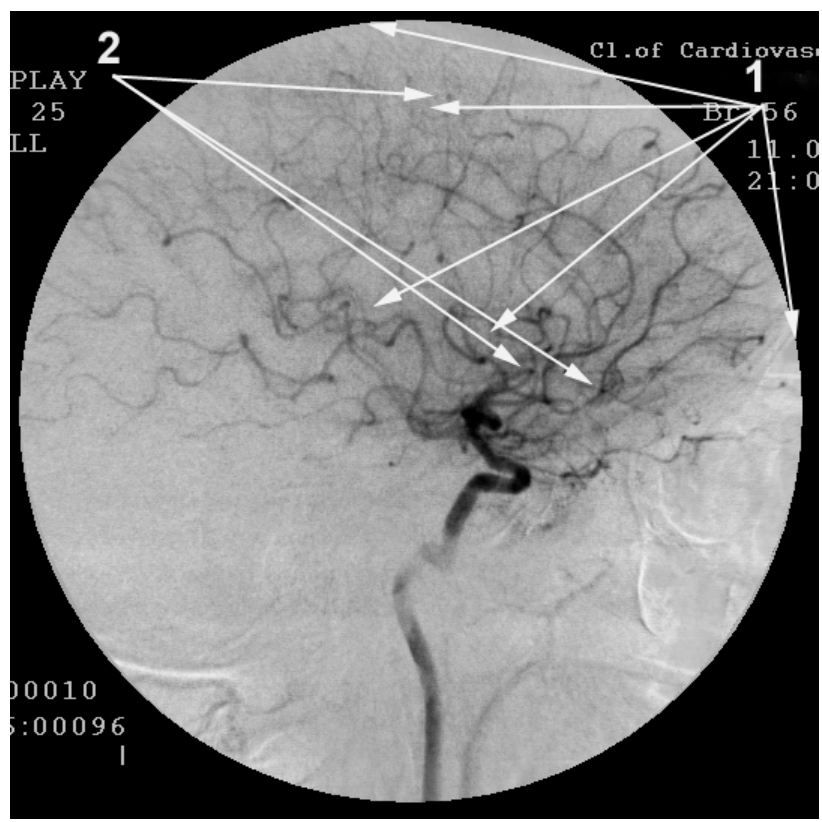

Figure 1. Patient A, 56 years old, male, (TDR-2), before transcatheter treatment. Left internal carotid artery angiogram, frame 96 (3.84 seconds after the contrasting phase started), arterial phase. 1. Hypovascular zones in the temporal and frontoparietal regions; 2. Multiple arteriovenous shunts in the temporal and frontoparietal regions.

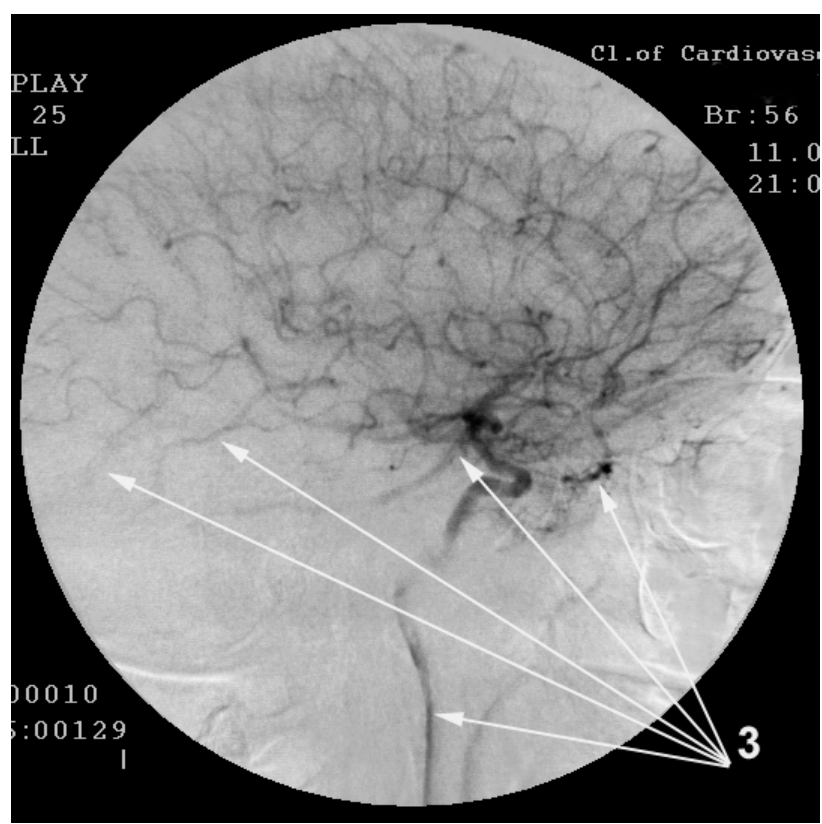

Figure 2. Same Patient A, 56 years old, male, (TDR-2), before transcatheter treatment. Left internal carotid artery angiogram, frame 129 (5.16 seconds after the contrasting phase started), arterial phase. Dumping of arterial blood into the venous bed through arteriovenous shunts. 3. Simultaneous contrasting of arteries and veins.

\subsubsection{Early Period after the Treatment (1 - 6 Months)}

Group TDR-0:

According to SG, 3 (75.00\%) patients had complete recovery of blood flow velocity in the cerebral hemispheres, and 1 (25.00\%) patient had incomplete recovery.

According to REG, 3 (75.00\%) patients had complete recovery of pulse blood volume in the cerebral hemis 


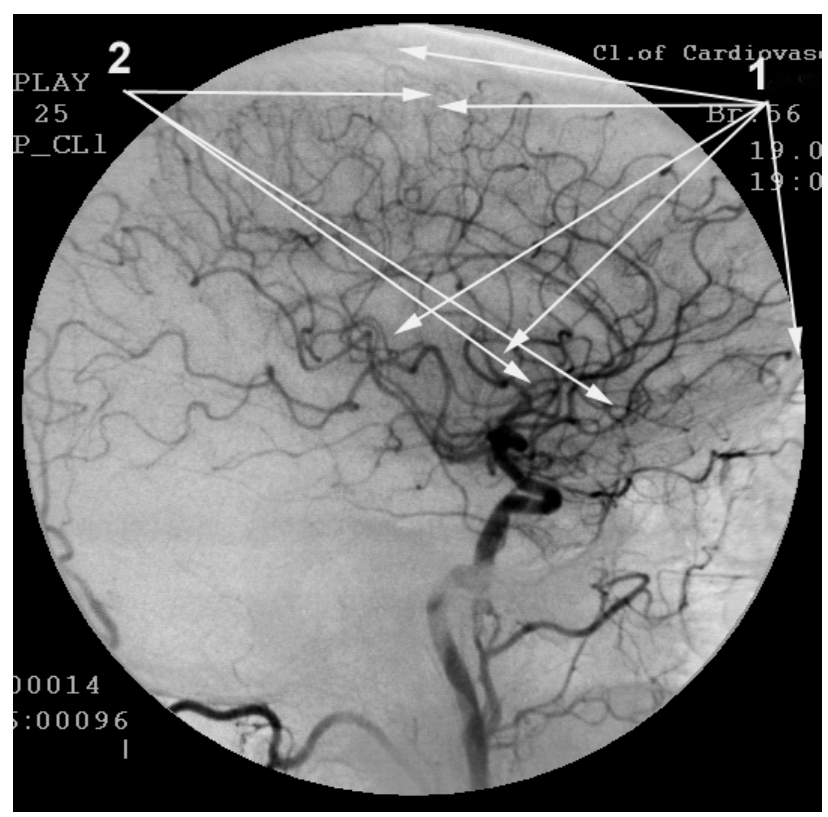

Figure 3. Same Patient A, 56 years old, after transcatheter treatment. Left internal carotid artery angiogram, frame 96 (3.84 seconds after the contrasting phase started), arterial phase. 1. Angiogenesis stimulation, recovery of the collateral and capillary bed in the temporal and frontoparietal regions. 2. Reduction of multiple arteriovenous shunts in the temporal and frontoparietal regions.

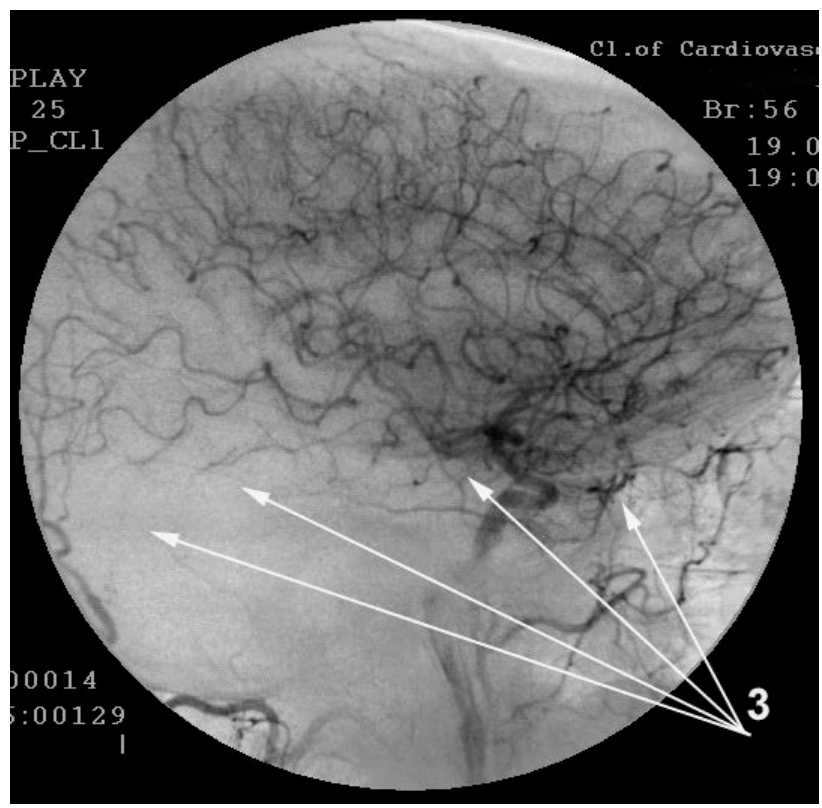

Figure 4. Same Patient A, 56 years old, after transcatheter treatment. Left internal carotid artery angiogram, frame 129 (5.16 seconds after the contrasting phase started), arterial phase. Reduction of arteriovenous shunts in the temporal and frontoparietal regions. 3. Absence of simultaneous contrasting of arteries and veins.

pheres, and 1 (25.00\%) patient had insignificantly reduced parameters.

According to CT and MRI, 4 (100\%) patients had an increase in the tissue mass of the temporal lobes of the brain, which was accompanied by narrowing of the Sylvian fissure and subarachnoid space in the frontoparietal and temporal regions.

Clinically, memory improvement and cognitive function recovery of up to 28 - 30 points were observed. 
Group TDR-1:

According to SG, 12 (80.00\%) patients had almost complete recovery of blood flow in the cerebral hemispheres, and 3 (20.00\%) patients had incomplete recovery.

According to REG, 13 (86.67\%) patients had almost complete recovery of pulse blood volume in the cerebral hemispheres, and 2 patients (13.33\%) had incomplete recovery.

According to CT and MRI, all patients had an increase in the tissue mass of the temporal lobes of the brain, which was accompanied by narrowing of the Sylvian fissure and subarachnoid space in the frontoparietal and temporal regions.

Clinically, all patients had dementia reduction and cognitive functions recovery: 6 (40.00\%) patients—of up to 25 - 26 points, 9 (60.00\%) patients—of up to 27 - 28 points.

Group TDR-2:

According to SG, 15 (75.00\%) patients had almost complete recovery of blood flow in the cerebral hemispheres, and 5 (25.00\%) patients had incomplete recovery.

According to REG, $16(80.00 \%)$ patients had almost full recovery of pulse blood flow in the cerebral hemispheres, 2 patients (10.00\%) had incomplete recovery, and 2 (10.00\%) patients' results were above the norm by $6 \%-10 \%$.

According to CT and MRI, all patients showed an increase in the tissue mass of the temporal lobes of the brain, which was accompanied by narrowing of the Sylvian fissure and subarachnoid space in the frontoparietal and temporal regions.

Clinically, 11 (55.00\%) patients had dementia reduction and cognitive functions improvement of up to 19 - 20 points, 9 (45.00\%) patients—of up to 21 - 22 points.

Group TDR-3:

According to SG, 5 (71.43\%) patients had nearly complete recovery of blood flow in the cerebral hemispheres, 2 patients (28.57\%) had incomplete recovery.

According to REG, 2 (28.57\%) patients had nearly complete recovery of pulse blood flow in the cerebral hemispheres, and 5 (71.43\%) patients' results were above the norm by $6 \%-10 \%$.

According to CT and MRI, an increase in the tissue mass of the temporal lobes of the brain was detected in all 7 patients.

Clinically, all 7 (100\%) patients had dementia reduction and cognitive functions improvement of up to 11 - 12 points.

\subsubsection{Long Period after the Treatment (1 - 7 Years)}

According to SG and REG in the long term, the resulting positive trend continued throughout the observation.

Group TDR-0:

According to CT and MRI in the period of more than 1 year after the treatment, all 4 (100\%) cases showed regeneration of the tissue mass of the temporal lobes of the brain. Clinically, the patients showed sustained recovery of cognitive functions of up to the 28 - 30 points. All the patients were transferred to the group of practically healthy individuals. The effect maintained throughout the observation period (Table 1).

Group TDR-1:

According to CT and MRI in the period of more than 1 year after the treatment, all 15 (100\%) patients showed almost complete recovery of the tissue mass of the temporal lobes, with atrophy of $4 \%-8 \%$, which is the age norm. Clinically, the patients showed no signs of dementia and demonstrated sustained recovery of cognitive functions of up to 27 - 28 points. All the patients were transferred to Group TDR-0. The effect maintained throughout the observation period (Table 1).

Group TDR-2:

According to CT and MRI in the period of more than 1 year after the treatment, all 20 (100\%) cases showed an increase in the tissue mass of the temporal lobes. Clinically, it was accompanied by further dementia decline and cognitive functions improvement of up to 21 - 22 points. In the long-term period of more than 18 months, $11(55.00 \%)$ patients showed further growth of the tissue mass of the temporal lobes, with atrophy decrease to $15 \%$ - 18\%, which was also accompanied by dementia decline and cognitive functions improvement of up to 21 25 points. The remaining 9 (45.00\%) patients demonstrated no further dynamics. All the patients in this group were transferred to Group TDR-1. The stable condition lasted for about 4 years, after which the patients had cognitive decline to 20 - 21 points (Table 1 ). 
Table 1. Comparison of the clinical outcome obtained in test and control group patients after the treatment (statistical analysis).

\begin{tabular}{|c|c|c|c|c|c|c|c|c|}
\hline & & & Sun & imary Frequen & Icy Table & & & \\
\hline & $\begin{array}{l}\text { Treatment } \\
\text { Method }\end{array}$ & $\begin{array}{c}\text { Severity } \\
\text { Degree } \\
\text { before } \\
\text { Treatment }\end{array}$ & $\begin{array}{c}\text { Severity Degree } \\
\text { after Treatment } \\
\text { Healthy }\end{array}$ & $\begin{array}{c}\text { Severity } \\
\text { Degree after } \\
\text { Treatment } \\
\text { TDR-0 }\end{array}$ & $\begin{array}{c}\text { Severity } \\
\text { Degree after } \\
\text { Treatment } \\
\text { TDR-1 }\end{array}$ & $\begin{array}{c}\text { Severity } \\
\text { Degree after } \\
\text { Treatment } \\
\text { TDR-2 }\end{array}$ & $\begin{array}{c}\text { Severity } \\
\text { Degree after } \\
\text { Treatment } \\
\text { TDR-3 }\end{array}$ & $\begin{array}{l}\text { Total } \\
\text { Per } \\
\text { Line }\end{array}$ \\
\hline Frequency & transcatheter & TDR-0 & 4 & 0 & 0 & 0 & 0 & 4 \\
\hline$\%$ per column & & & $100.00 \%$ & $0.00 \%$ & $0.00 \%$ & $0.00 \%$ & & $8.70 \%$ \\
\hline$\%$ per line & & & $100.00 \%$ & $0.00 \%$ & $0.00 \%$ & $0.00 \%$ & $0.00 \%$ & $40.00 \%$ \\
\hline Total percentage & & & $4.49 \%$ & $0.00 \%$ & $0.00 \%$ & $0.00 \%$ & $0.00 \%$ & $4.49 \%$ \\
\hline Frequency & transcatheter & TDR-1 & 0 & 15 & 0 & 0 & 0 & 15 \\
\hline$\%$ per column & & & $0.00 \%$ & $100.00 \%$ & $0.00 \%$ & $0.00 \%$ & & $32.61 \%$ \\
\hline$\%$ per line & & & $0.00 \%$ & $100,00 \%$ & $0.00 \%$ & $0.00 \%$ & $0.00 \%$ & $53.57 \%$ \\
\hline Total percentage & & & $0.00 \%$ & $16.85 \%$ & $0.00 \%$ & $0.00 \%$ & $0.00 \%$ & $16.85 \%$ \\
\hline Frequency & transcatheter & TDR-2 & 0 & 0 & 20 & 0 & 0 & 20 \\
\hline \% per column & & & $0.00 \%$ & $0.00 \%$ & $100.00 \%$ & $0.00 \%$ & & $43.48 \%$ \\
\hline \% per line & & & $0.00 \%$ & $0.00 \%$ & $100.00 \%$ & $0.00 \%$ & $0.00 \%$ & $58.82 \%$ \\
\hline Total percentage & & & $0.00 \%$ & $0.00 \%$ & $22.47 \%$ & $0.00 \%$ & $0.00 \%$ & $22.47 \%$ \\
\hline Frequency & transcatheter & TDR-3 & 0 & 0 & 0 & 7 & 0 & 7 \\
\hline \% per column & & & $0.00 \%$ & $0.00 \%$ & $0.00 \%$ & $100.00 \%$ & & $15.22 \%$ \\
\hline$\%$ per line & & & $0.00 \%$ & $0.00 \%$ & $0.00 \%$ & $100.00 \%$ & $0.00 \%$ & $41.18 \%$ \\
\hline Total percentage & & & $0.00 \%$ & $0.00 \%$ & $0.00 \%$ & $7.87 \%$ & $0.00 \%$ & $7.87 \%$ \\
\hline Frequency & Total & & 4 & 15 & 20 & 7 & $\mathbf{0}$ & 46 \\
\hline \% per column & & & $100.00 \%$ & $83.33 \%$ & $80.00 \%$ & $38.89 \%$ & $0.00 \%$ & \\
\hline$\%$ per line & & & $8.70 \%$ & $32.61 \%$ & $43.48 \%$ & $15.22 \%$ & $0.00 \%$ & \\
\hline Total percentage & & & $4.49 \%$ & $16.85 \%$ & $22.47 \%$ & $7.87 \%$ & $0.00 \%$ & $51.69 \%$ \\
\hline Frequency & therapeutic & TDR-0 & 0 & 3 & 3 & 0 & 0 & 6 \\
\hline$\%$ per column & & & & $100.00 \%$ & $60.00 \%$ & $0.00 \%$ & $0.00 \%$ & $13.95 \%$ \\
\hline$\%$ per line & & & $0.00 \%$ & $50.00 \%$ & $50.00 \%$ & $0.00 \%$ & $0.00 \%$ & $60.00 \%$ \\
\hline Total percentage & & & $0.00 \%$ & $3.37 \%$ & $3.37 \%$ & $0.00 \%$ & $0.00 \%$ & $6.74 \%$ \\
\hline Frequency & therapeutic & TDR-1 & 0 & 0 & 2 & 11 & 0 & 13 \\
\hline$\%$ per column & & & & $0.00 \%$ & $40.00 \%$ & $100.00 \%$ & $0.00 \%$ & $30.23 \%$ \\
\hline \% per line & & & $0.00 \%$ & $0.00 \%$ & $15.38 \%$ & $84.62 \%$ & $0.00 \%$ & $46.43 \%$ \\
\hline Total percentage & & & $0.00 \%$ & $0.00 \%$ & $2.25 \%$ & $12.36 \%$ & $0.00 \%$ & $14.61 \%$ \\
\hline Frequency & therapeutic & TDR-2 & 0 & 0 & 0 & 0 & 14 & 14 \\
\hline$\%$ per column & & & & $0.00 \%$ & $0.00 \%$ & $0.00 \%$ & $58.33 \%$ & $32.56 \%$ \\
\hline$\%$ per line & & & $0.00 \%$ & $0.00 \%$ & $0.00 \%$ & $0.00 \%$ & $100.00 \%$ & $41.18 \%$ \\
\hline Total percentage & & & $0.00 \%$ & $0.00 \%$ & $0.00 \%$ & $0.00 \%$ & $15.73 \%$ & $15.73 \%$ \\
\hline Frequency & therapeutic & TDR-3 & 0 & 0 & 0 & 0 & 10 & 10 \\
\hline$\%$ per column & & & & $0.00 \%$ & $0.00 \%$ & $0.00 \%$ & $41.67 \%$ & $23.26 \%$ \\
\hline \% per line & & & $0.00 \%$ & $0.00 \%$ & $0.00 \%$ & $0.00 \%$ & $100,00 \%$ & $58.82 \%$ \\
\hline Total percentage & & & $0.00 \%$ & $0.00 \%$ & $0.00 \%$ & $0.00 \%$ & $11.24 \%$ & $11.24 \%$ \\
\hline Frequency & Total & & $\mathbf{0}$ & 3 & 5 & 11 & 24 & 43 \\
\hline$\%$ per column & & & $0.00 \%$ & $16.67 \%$ & $20.00 \%$ & $61.11 \%$ & $100.00 \%$ & \\
\hline \% per line & & & $0.00 \%$ & $6.98 \%$ & $11.63 \%$ & $25.58 \%$ & $55.81 \%$ & \\
\hline Total percentage & & & $0.00 \%$ & $3.37 \%$ & $5.62 \%$ & $12.36 \%$ & $26.97 \%$ & $48.31 \%$ \\
\hline Frequency & Column sums & & 4 & 18 & 25 & 18 & 24 & 89 \\
\hline Total percentage & & & $4.49 \%$ & $20.22 \%$ & $28.09 \%$ & $20.22 \%$ & $26.97 \%$ & \\
\hline
\end{tabular}

The original data, the distribution of which is given in the summary table, were analyzed using the nonparametric Mann-Whitney test. The statistical analysis showed that at the beginning of the therapy there were no significant differences between the Test and Control Groups ( $\mathrm{p}>0.05$ ), while after the treatment these differences became significant $(\mathrm{p}<0.01)$. The analysis of the indicator dynamics by means of the Mann-Whitney test also revealed significant differences between the groups: the effect of the therapy in the Test Group was significantly higher than in the Control Group (p < 0.01 ). 
Group TDR-3:

According to CT and MRI in the period of more than 1 year after the treatment, all 7 (100\%) cases showed an increase in the tissue mass of the temporal lobes of the brain, which was accompanied by a decrease in atrophy in these regions of up to $28 \%$ - 34\%. Clinically, all patients had dementia decline and partial improvement of cognitive functions: 4 (57.14\%) patients—of up to 11 - 14 points, $3(42.86 \%)$ patients—of up to 15 - 19 points. 5 (71.43\%) patients were transferred to Group TDR-2. The stable condition lasted for about 2 - 2.5 years, and then the testing showed a decline to $11-12$ points (Table 1).

According to cerebral MUGA (Test Group), all 8 (17.39\%) reexamined patients had progression of angiogenesis along with retention of the collateral and capillary bed and the reduction of arteriovenous shunts for 2 - 6 years after the transcatheter treatment.

\subsection{Control Group}

\subsubsection{Early after the Treatment (1 - 6 Months)}

According to SG and REG in the early period of observation, all patients in the control group had a weak positive reaction of the speed of blood flow and pulse blood filling in the cerebral hemispheres. According to CT and MRI, no dynamics was observed. Clinically, patients in Group TDR-0 showed a tendency to improve memory and restore cognitive functions to 27 - 28 points.

\subsubsection{Remote Period after the Treatment ( 1 - 7 Years) \\ Group TDR-0:}

According to SG and REG, the patients retained a weak positive reaction of the blood flow velocity and pulse blood filling in the cerebral hemispheres.

Clinically, memory improvement and stabilization of cognitive functions remained for 2 years after the beginning of the treatment. In the same period, according to CT and MRI, 1 (16.67\%) patient had no changes in the tissue mass of the temporal lobes, $3(50.00 \%)$ patients showed a tendency to the tissue mass decrease, 2 (33.33\%) patients had progressive reduction of the tissue mass to $14 \%-18 \%$. In the longer-term period, the tendency to increasing atrophy symptoms persisted. In the period of over 2 years, $3(50.00 \%)$ patients did not reveal any signs of dementia, $3(50.00 \%)$ patients confronted the appearance of dementia symptoms, along with cognitive functions decrease to 24 - 25 points. These patients were transferred to Group TDR-1 (Table 1).

Group TDR-1:

According to SG and REG, the patients retained a weak positive reaction of the blood flow velocity and pulse blood filling.

Clinically, for a period of 2 to 3 years after the beginning of the treatment, the patients showed the stabilization of dementia and cognitive functions. For the period of more than 2 - 3 years, according to CT and MRI, all $13(100 \%)$ patients had growing atrophic process with the tissue mass of the temporal lobes decrease to $12 \%$ 24\%. These were accompanied by dementia growth and cognitive functions decline: 2 (15.38\%) patients- to 20 21 points, 11 (84.62\%) patients - to 18 - 19 points. The latter patients were transferred to Group TDR-2 (Table 1).

Group TDR-2:

Clinically, all 14 (100\%) patients showed stabilized condition for a period of up to six months; in a longer period, the patients had dementia growth and cognitive functions decline to $11-12$ points. According to SG and REG, 9 (64.29\%) patients had deterioration in cerebral blood flow velocity and pulse blood volume, 5 (35.71\%) patients had no changes in the parameters. According to CT and MRI in the period of more than $1-2$ years after the beginning of the treatment, all $14(100 \%)$ patients had growing atrophic process with a decrease in the tissue mass of the temporal lobes to $33 \%-40 \%$ and cognitive functions decline to $9-11$ points. All the patients were transferred to Group TDR-3 (Table 1).

Group TDR-3:

Clinically, all 10 patients had dementia growth and increasing cognitive disorders. According to SG and REG in the period of more than 1 - 2 years, $3(30.00 \%)$ patients had a slight improvement of cerebral blood flow velocity and pulse blood volume, $7(70.00 \%)$ patients showed no marked changes in the parameters. Cognitive functions condition was reduced to 7 - 8 points. According to CT and MRI in the period of more than 1 - 2 years after the beginning of the treatment, all 10 patients had growing atrophic process with a decrease in the tissue mass of the temporal lobes to $40 \%$ - $55 \%$ (Table 1 ). 


\section{Discussion}

Taking into account the seriousness of the problem, the question of the importance of the vascular factor in the etiology and pathogenesis of AD was considered at all the latest Congresses of the International Society to Advance Alzheimer Research and Treatment (ISTAART).

The intensity of dyscirculatory angiopathy of Alzheimer's type (DAAT) does not depend on the stage of the disease. Both at TDR-0 stage and at TDR-1, TDR-2, TDR-3 stages, the type and the degree of vascular lesions are identical [10] [14] [22] [23]. The development of the vascular dysfunction leads not only to capillary circulation disorders, but also to the accumulation of beta amyloid and progressive cerebral atrophy development [25] [26]. The severity of $\mathrm{AD}$, dementia, cognitive impairment and the condition of higher mental functions of the patient are directly dependent on the severity of atrophic changes in the brain tissue [10] [23] [40]. Patients with the pre-clinical stage of the disease (TDR-0) have atrophic changes of the temporal lobes of $4 \%-8 \%$, but the degree of atrophy increases to $33 \%$ - 64\% in patients with the advanced AD stage (TDR-3) [8] [30] [40].

The desire to improve the metabolic process in the brain, to restore the removal of amyloid beta or to reduce its content one way or another, is futile without the restoration of blood supply to the tissues. The problem of $\mathrm{AD}$ treatment must be solved comprehensively.

The mechanism of low laser energy effect on the vascular wall and the vascular bed is in the powerful stimulation of the process of natural physiological angiogenesis causing collateral and capillary revascularization [20] [46]-[50]. Restoration of blood supply improves brain nutrition, reduces hypoxic conditions, which in turn improves the removal of amyloid beta, contributes to the normalization of its metabolism in the cerebral tissue. Simultaneously, laser energy stimulates metabolism in neurons enhancing their energy resource by the stimulating effect on mitochondria and thereby providing neuroprotection [20]. The subsequent increase in the tissue mass of the temporal lobes of the brain after transcatheter treatment shows the development of regenerative process in its tissues [20] [38] [51].

These findings are supported by research of many authors who conducted both experimental and clinical work on transcranial low-energy laser effects on the brain in $\mathrm{AD}$ and other neurodegenerative lesions [35]-[38] [52]-[55]. It should be noted that the cranial bones have a high optical density and absorb most of the laser light, and therefore, the effectiveness of treatment with transcranial laser exposure is much lower than that of the transcatheter method.

All Test Group patients demonstrate long-lasting positive outcome after the transcatheter treatment. It allowed withdrawing some patients (group TDR-0) out of the limits of the scale, to healthy individuals, and other patients (groups TDR-1, TDR-2, TDR-3) to group TDR of an earlier stage (Table 1).

Patients with early-stage disease and less severe atrophic changes in the tissue of the temporal lobes of the brain (groups TDR-0 and TDR-1) had long-lasting positive outcome during the observation period (up to 7 years). Patients with more advanced and severe AD stages (groups TDR-2, TDR-3) had a pronounced positive effect for 2.5 - 4 years, after which there was a cognitive decline due to more severe atrophic changes in the tissue of the temporal lobes.

The treatment of Control Group patients was carried out following common therapeutic schemes. The use of vasoactive drugs did not give the desired effect. No long-lasting positive effect was achieved in any case after this treatment. Patients with early-stage disease (groups TDR-0 and TDR-1) had stabilized condition for a period of 2-3 years, and then there developed growing atrophic changes in the tissue of the temporal lobes of the brain, accompanied by increased cognitive impairment. Patients with more advanced AD stages (groups TDR-2, TDR3) had stabilized condition for a short period or none at all, and at the same time atrophic changes increased in the tissue of the temporal lobes, accompanied by growing cognitive disorders and dementia. These data correspond to those obtained by other authors [44] [45].

Transcatheter AD treatment by means of low-energy laser is effective, etiologically and pathogenetically substantiated treatment for AD. The method is not traumatic — we did not have any complications or deaths even during the treatment of heavy patients. The risk of transcatheter intervention is low enough; it can be used at all stages of the disease, while its efficiency is much higher than that of common therapies. The proposed method can reduce the level of dementia and cognitive impairment. We cannot exclude that transcatheter treatment of patients with a preclinical AD stage (TDR-0) and of those with an early stage of the disease (TDR-1) can prevent further appearance or progression of the disease. Treating patients with more advanced AD stages (TDR-2, TDR-3) gives an opportunity to slow down further progression of the disease for a long time and to cause its regress. 


\section{Conflict of Interest}

The authors declare no conflict of interest.

\section{References}

[1] 2015 Alzheimer's Disease Facts and Figures. https://www.alz.org/facts/downloads/facts figures 2015.pdf

[2] Altman, R. and Rutledge, J.C. (2010) The Vascular Contribution to Alzheimer's Disease. Clinical Science, 119, 407421. http://dx.doi.org/10.1042/CS20100094 http://www.ncbi.nlm.nih.gov/pmc/articles/PMC2950620/?tool=pubmed

[3] Sakai, K., Boche, D., Carare, R., Johnston, D., Holmes, C., Love, S. and Nicoll, J.A.R. (2014) A $\beta$ Immunotherapy for Alzheimer's Disease: Effects on apoE and Cerebral Vasculopathy. Acta Neuropathologica, 128, 777-789. http://dx.doi.org/10.1007/s00401-014-1340-9 http://link.springer.com/article/10.1007/s00401-014-1340-9 doi: 10.1007/s00401-014-1340-9

[4] Morel, F. (1950) An Apparently Dyshoric and Topical Angiopathy. Monatsschr Psychiat Neurol, 120, 352-357. http://www.ncbi.nlm.nih.gov/pubmed/14806299

[5] De la Torre, J.C. (1997) Hemodynamic Consequences of Deformed Microvessels in the Brain in Alzheimer's Disease. Annals of New York Academy Sciences, 26, 75-91. http://www.ncbi.nlm.nih.gov/pubmed/9329682?dopt=Abstract

[6] Skoog, I., Kalaria, R.N. and Breteler, M.M. (1999) Vascular Factors and Alzheimer Disease. Alzheimer Disease and Associated Disorders. 13, 106-114. http://dx.doi.org/10.1097/00002093-199912003-00016

[7] Kalaria, R.N. (2000) Vascular Factors in Alzheimer's Disease. New York Academy of Sciences, New York. http://books.google.ru/books?id=jHZFAAAAYAAJ\&hl=ru\&source=gbs_book_similarbooks

[8] Maksimovich, I.V. (2008) Radiodiagnostics of Alzheimer's Disease. Diagnostics and Intervention Radiology, 2, 27-38. http://radiology-diagnos.ru/sites/default/files/vol2_4_2008_p25-36.pdf

[9] De la Torre, J.C. and Stefano, G.B. (2000) Evidence That Alzheimer’s Disease Is a Microvascular Disorder: The Role of Constitutive Nitric Oxide. Brain Research Reviews, 34, 119-136. http://www.ncbi.nlm.nih.gov/pubmed/11113503

[10] Maksimovich, I.V. (2011) Dyscirculatory Angiopathy of Alzheimer’s Type. Journal of Behavioral and Brain Science, 1, 57-68. http://www.scirp.org/journal/PaperInformation.aspx?paperID=4630 http://dx.doi.org/10.4236/jbbs.2011.12008

[11] Grammas, P., Sanchez, A., Tripathy, D., Luo, E. and Martinez, J. (2011) Vascular Signaling Abnormalities in Alzheimer Disease. Cleveland Clinic Journal of Medicine, 78, 50-53. http://www.ncbi.nlm.nih.gov/pubmed/21972332 http://dx.doi.org/10.3949/ccjm.78.s1.09

[12] Baloiannis, S.J. and Baloiannis, I.S. (2012) The Vascular Factor in Alzheimer's Disease: A Study in Golgi Technique and Electron Microscopy. Journal of the Neurological Sciences, 322, 117-121.

http://www.jns-journal.com/article/S0022-510X(12)00344-9/abstract http://dx.doi.org/10.1016/j.jns.2012.07.010

[13] Mielke, M.M., Rosenberg, P.B., Tschanz, J.L., Cook, L., et al. (2007) Vascular Factors Predict Rate of Progression in Alzheimer Disease. Neurology, 6, 1850-1858. http://www.neurology.org/content/69/19/1850.short http://dx.doi.org/10.1212/01.wnl.0000279520.59792.fe

[14] Maksimovich, I.V. (2013) Importance of Vascular Factors in the Etiology and Pathogenesis of Alzheimer's Disease. Alzheimer's \& Dementia, 9, 378-379. http://www.alzheimersanddementia.com/article/S1552-5260(13)01396-4/abstract http://dx.doi.org/10.1016/j.jalz.2013.05.739

[15] Grammas, P., Martinez, J., Sanchez, P., Yin, X., Riley, J., Gay, D., Desobry, K., Tripathy, D., Luo, J., Evola, M. and Young, A. (2014) A New Paradigm for the Treatment of Alzheimer's Disease: Targeting Vascular Activation. Journal of Alzheimer's Disease, 40, 619-630. http://www.ncbi.nlm.nih.gov/pubmed/24503617

[16] De la Torre, J.C. (2012) A Turning Point for Alzheimer’s Disease? Biofactors, 38, 78-83. http://www.ncbi.nlm.nih.gov/pubmed?term=De\%20la\%20Torre\%20J.\%20C.\%20(2012)\%20A\%20turning\%20point\% 20for\%20Alzheimer's\%20disease\%3F http://dx.doi.org/10.1002/biof.200

[17] Gjulev, N.M., Pustozertsev, V.G. and Gjulev, S.N. (2002) Cerebrovascular Diseases. BINOM, Moscow. http://www.combook.ru/product/158808/

[18] Luzha, D. (1973) X-Ray Anatomy of the Vascular System. Hungarian Academy of Sciences Publishing House, Budapest. http://www.twirpx.com/file/378198/

[19] Folkow, B. and Neil, E. (1971) Circulation. Oxford University Press, London-Toronto. http://books.google.ru/books/about/\%E5\%BE\%AA\%E7\%92\%B0.html?hl=ru\&id=KkQmNQEACAAJ 
[20] Maksimovich, I.V. (2004) Transluminal Laser Angioplasty in Treatment of Ischemic Lesions of a Brain. M.D. Dissertation, Russian University of Friendship of the People, Moscow. http://disseng.com/page/order/id/206426.html

[21] Maksimovich, I.V, and Gotman, L.N. (2006) Method of Complex Radiation Diagnostics at Preclinical and Clinical Stages of Alzheimer's Disease. Russian Patent No. 2315559. http://bankpatentov.ru/node/28577

[22] Maksimovich, I.V. (2010) Dyscirculatory Angiopathy of the Brain of Alzheimer’s Type. Alzheimer's \& Dementia, 6, e34. http://www.alzheimersanddementia.com/article/S1552-5260(10)02300-9/fulltext http://dx.doi.org/10.1016/j.jalz.2010.08.108

[23] Maksimovich, I V. (2012) Vascular Factors in Alzheimer's Disease. Health, 4, 735-742. http://www.scirp.org/journal/PaperInformation.aspx?paperID=23274 http://dx.doi.org/10.4236/health.2012.429114

[24] Maksimovich, I.V. (2013) Disorders of Cerebrovascular Angioarchitectonics and Microcirculation in the Etiology and Pathogenesis of Alzheimer's Disease. Advances in Alzheimer's Disease, 2, 171-181. http://www.scirp.org/Journal/PaperInformation.aspx?paperID=40410\&\#abstract http://dx.doi.org/10.4236/aad.2013.24022

[25] Bell, R.D. and Zlokovic, B.V. (2009) Neurovascular Mechanisms and Blood-Brain Barrier Disorder in Alzheimer's Disease. Acta Neuropathologica, 118, 103-113. http://www.ncbi.nlm.nih.gov/pubmed/19319544 http://dx.doi.org/10.1007/s00401-009-0522-3

[26] Zlokovic, B.V. (2011) Neurovascular Pathways to Neurodegeneration in Alzheimer's Disease and Other Disorders. Nature Reviews Neuroscience, 12, 723-738. http://www.ncbi.nlm.nih.gov/pubmed/22048062 http://dx.doi.org/10.1038/nrn3114

[27] Provenzano, F.A., Muraskin, J., Tosto, G., Narkhede, A., Wasserman, B.T., Griffith, E.Y., Guzman, V.A., Meier, I.B., Zimmerman, M.E. and Brickman, A.M. (2013) White Matter Hyperintensities and Cerebral Amyloidosis: Necessary and Sufficient for Clinical Expression of Alzheimer Disease? JAMA Neurology, 70, 455-461.

http://www.ncbi.nlm.nih.gov/pubmed/23420027 http://dx.doi.org/10.1001/jamaneurol.2013.1321

[28] Nishimura, T., Hashikawa, K., Fukuyama, H., Kubota, T., Kitamura, S., Matsuda, H., Hanyu, H., Nabatame, H., Oku, N., Tanabe, H., Kuwabara, Y., Jinnouchi, S. and Kubol, A. (2007) Decreased Cerebral Blood Flow and Prognosis of Alzheimer's Disease: A Multicenter HMPAO-SPECT Study. Annals of Nuclear Medicine, 21, 15-23. http://www.ncbi.nlm.nih.gov/pubmed/17373332 http://dx.doi.org/10.1007/bf03033995

[29] Maksimovich, I.V. and Polyaev, Y.A. (2010) The Importance of Early Diagnosis of Dyscircular Angiopathy of Alzheimer's Type in the Study of Heredity of Alzheimer's Disease. Alzheimer's \& Dementia, 6, e43. http://www.alzheimersanddementia.com/article/S1552-5260(10)02325-3/abstract http://dx.doi.org/10.1016/j.jalz.2010.08.133

[30] Maksimovich, I.V. (2012) Certain New Aspects of Etiology and Pathogenesis of Alzheimer's Disease. Advances in Alzheimer's Disease, 1, 68-76. http://www.scirp.org/journal/PaperInformation.aspx?PaperID=25962 http://dx.doi.org/10.4236/aad.2012.13009

[31] Knickmeyer, R.C., Wang, J., Zhu, H., Geng, X., Woolson, S., Hamer, R.M., Konneker, T., Lin, W., Styner, M. and Gilmore, J.H. (2013) Common Variants in Psychiatric Risk Genes Predict Brain Structure at Birth. Cerebral Cortex, 1, 2. http://cercor.oxfordjournals.org/content/early/2013/01/02/cercor.bhs401.full.pdf+html

[32] Maksimovich, I.V. (2006) Method for Endovascular Treatment of Alzheimer's Disease. Russian Patent No. 2297860. http://worldwide.espacenet.com/publicationDetails/originalDocument?FT=D\&date=20070427\&DB=EPODOC\& locale=en_EP\&CC=RU\&NR=2297860C1\&KC=C1

[33] Maksimovich, I.V. (2008) Method and Device for Endovascular Treatment of Alzheimer’s Disease. US Patent No. 7389776. http://www.freepatentsonline.com/7389776.pdf

[34] Maksimovich, I.V. (2012) Endovascular Application of Low-Energy Laser in the Treatment of Dyscirculatory Angiopathy of Alzheimer's Type. Journal of Behavioral and Brain Science, 2, 67-81. http://www.scirp.org/Journal/PaperInformation.aspx?paperID=17730\&\#abstract http://dx.doi.org/10.4236/jbbs.2012.21008

[35] Yang, X., Askarova, S., Sheng, W., et al. (2010) Low Energy Laser Light (632.8 nm) Suppresses Amyloid- $\beta$ PeptideInduced Oxidative and Inflammatory Responses in Astrocytes. Neuroscience, 171, 859-868. http://www.sciencedirect.com/science/article/pii/S030645221001273X?np=y

[36] Naeser, M.A. and Hamblin, M.R. (2011) Potential for Transcraniallaser or LED Therapy to Treatstroke, Traumatic Brain Injury, and Neurodegenerative Disease. Photomedicine and Laser Surgery, 29, 443-446.

http://www.ncbi.nlm.nih.gov/pubmed/21728786

http://dx.doi.org/10.1089/pho.2011.9908 
[37] Song, S., Zhou, F. and Chen, W. R. (2012) Low-Level Laser Therapy Regulates Microglial Function through Src-Mediated Signaling Pathways: Implications for Neurodegenerative Diseases. Journal of Neuroinflammation, 18, 219. http://www.ncbi.nlm.nih.gov/pubmed/22989325 http://dx.doi.org/10.1186/1742-2094-9-219

[38] Barrett, D.W. and Gonzalez-Lima, F. (2013) Transcranial Infrared Laser Stimulation Produces Beneficial Cognitive and Emotional Effects in Humans. Neuroscience, 29, 13-23. http://www.ncbi.nlm.nih.gov/pubmed/23200785 http://dx.doi.org/10.1016/j.neuroscience.2012.11.016

[39] Maksimovich, I.V. (2012) The Tomography Dementia Rating Scale: Morphologically Determined Scale of Alzheimer's Disease Stages. Alzheimer's \& Dementia, 8, 335-336. http://www.alzheimersanddementia.com/article/S1552-5260(12)01059-X/fulltext

[40] Maksimovich, I.V. (2012) The Tomography Dementia Rating Scale (TDR)—The Rating Scale of Alzheimer's Disease Stages. Health, 4, 712-719. http://www.scirp.org/journal/PaperInformation.aspx?PaperID=23257 http://dx.doi.org/10.4236/health.2012.429111

[41] Morris, J.C. (1993) The Clinical Dementia Rating (CDR): Current Version and Scoring Rules. Neurology, 11, 24122414. http://www.ncbi.nlm.nih.gov/pubmed/8232972 http://dx.doi.org/10.1212/wnl.43.11.2412-a

[42] Folstein, M.F., Folstein, S.E. and McHugh, P.R. (1975) “Mini-Mental State”. A Practical Method for Grading the Cognitive State of Patients for the Clinician. Journal of Psychiatric Research, 12, 189-198. http://www.ncbi.nlm.nih.gov/pubmed/1202204 http://dx.doi.org/10.1016/0022-3956(75)90026-6

[43] Maksimovich, I.V. Gotman, L.N. and Masyuk, S.M. (2006) Method of Determining Dimensions of Temporal Brain Lobes in Patients Suffering from Alzheimer’s Disease. Russian Patent No. 2306102.

http://worldwide.espacenet.com/publicationDetails/biblio?DB=EPODOC\&adjacent=true\&locale=en EP\&FT=D\&date $=20070920 \& \mathrm{CC}=\mathrm{RU} \& \mathrm{NR}=2306102 \mathrm{C} 1 \& \mathrm{KC}=\mathrm{C} 1$

[44] Matsunaga, S., Kishi, T. and Iwata, N. (2014) Combination Therapy with Cholinesterase Inhibitors and Memantine for Alzheimer's Disease: A Systematic Review and Meta-Analysis. International Journal of Neuropsychopharmacology, 18, pii: pyu 115. http://www.ncbi.nlm.nih.gov/pubmed/25548104 http://dx.doi.org/10.1016/j.jalz.2014.05.1710

[45] Grossberg, G.T., Farlow, M.R., Meng, X. and Velting, D.M. (2015) Evaluating High-Dose Rivastigmine Patch in Severe Alzheimer's Disease: Analyses with Concomitant Memantine Usage as a Factor. Current Alzheimer Research, 12, 53-60. http://www.ncbi.nlm.nih.gov/pubmed/25523430 http://dx.doi.org/10.2174/1567205011666141218122835

[46] Wilkinson, D. (2001) Drugs for Treatment of Alzheimer’s Disease. International Journal of Clinical Practice, 55, 129134. http://www.ncbi.nlm.nih.gov/pubmed/11321852

[47] Maksimovich, I.V. (2012) Transcatheter Treatment of Atherosclerotic Lesions of the Brain Complicated by Vascular Dementia Development. World Journal of Neuroscience, 2, 200-209. http://www.scirp.org/journal/PaperInformation.aspx?PaperID=24664 http://dx.doi.org/10.4236/wjns.2012.24031

[48] Chizhov, G.K., Kovalskaia, N.I. and Kozlov, V.I. (1991) The Effect of Helium-Neon Laser Radiation on the energy Metabolic Indices of the Myocardium. Bulletin of Experimental Biology and Medicine, 111, 302-305. http://www.ncbi.nlm.nih.gov/pubmed/2054512

[49] Kozlov, V.I. and Azizov, G.A. (2007) Pathophysiological Characteristics of Microcirculatory Disorders in Chronic Arterial Ischaemia of Lower Limbs. Angiology and Vascular Surgery, 13, 17-23. http://www.ncbi.nlm.nih.gov/pubmed/17679971 http://dx.doi.org/10.1007/BF00840904

[50] Moskvin, S.V. (2008) System Analysis of Efficiency in Controlling Biological Systems with Low-Energy Laser Radiation. Doctor Thesis, Tula. http://www.dissers.info/disser_323120.html

[51] Mak, M.C. and Cheing, G.L. (2012) Immediate Effects of Monochromatic Infrared Energy on Microcirculation in Healthy Subjects. Photomedicine and Laser Surgery, 30, 193-199. http://www.ncbi.nlm.nih.gov/pubmed/?term=Mak+MC\%2C+Cheing+GL. http://dx.doi.org/10.1089/pho.2011.3012

[52] Starck, T., Nissilä, J., Aunio, A., Abou-Elseoud, A., Remes, J., Nikkinen, J., Timonen, M., Takala, T., Tervonen, O. and Kiviniemi, V. (2012) Stimulating Brain Tissue with Bright Light Alters Functional Connectivity in Brain at the Resting State. World Journal of Neuroscience, 2, 81-90.

http://www.scirp.org/Journal/PaperInformation.aspx?paperID=19417\&\#abstract http://dx.doi.org/10.4236/wjns.2012.22012 
[53] Hashmi, J.T., Huang, Y.Y., Osmani, B.Z., et al. (2010) Role of Low-Level Laser Therapy in Neurorehabilitation, PM \& R, 2, S292-S305. http://www.ncbi.nlm.nih.gov/pmc/articles/PMC3065857/

[54] Stephan, W., Banas, L.J., Bennett, M. and Tunceroglu, H. (2012) Efficacy of Super-Pulsed 905 nm Low Level Laser Therapy (LLLT) in the Management of Traumatic Brain Injury (TBI): A Case Study. World Journal of Neuroscience, 2, 231-233. http://www.scirp.org/journal/PaperInformation.aspx?paperID=24793\&\#abstract http://dx.doi.org/10.4236/wjns.2012.24035

[55] Konstantinović, L.M., Jelić, M.B., Jeremić, A., Stevanović, V.B., Milanović, S.D. and Filipović, S.R. (2013) Transcranial Application of Near-Infrared Low-Level Laser Can Modulate Cortical Excitability. Lasers in Surgery and Medicine, 45, 648-653. http://www.ncbi.nlm.nih.gov/pubmed/24136303

http://dx.doi.org/10.1002/lsm.22190 